\title{
Antitumor activity of the synthetic retinoid ST1926 on primary effusion lymphoma in vitro and in vivo models
}

\author{
LOUNA KARAM $^{1,2}$, BILAL HOUSHAYMI ${ }^{1}$, RANA ABDEL-SAMAD ${ }^{3,4}$, MARIAM JAAFAR $^{1}$, IMAN HALLOUM $^{1}$, \\ CLAUDIO PISANO $^{5}$, FRANK NEIPEL ${ }^{2}$, NADINE DARWICHE $^{3}$ and RAGHIDA ABOU MERHI ${ }^{1}$ \\ ${ }^{1}$ Genomic and Health/EDST-PRASE Laboratory, Faculty of Sciences, R. Hariri Campus, Lebanese University, Hadath 1003, \\ Lebanon; ${ }^{2}$ Virologisches Institut, Universitätsklinikum Erlangen, D-91054 Erlangen, Germany; \\ ${ }^{3}$ Department of Biochemistry and Molecular Genetics, American University of Beirut, Beirut 1107-2020; \\ ${ }^{4}$ Faculty of Health Sciences, University of Balamand, Beirut 1100-2807, Lebanon; \\ ${ }^{5}$ Biogem, Research Institute, Ariano Irpino (AV) 83031, Italy
}

Received June 12, 2017; Accepted November 28, 2017

DOI: $10.3892 /$ or.2017.6137

\begin{abstract}
Primary effusion lymphoma (PEL) is a rare B-cell neoplasm, associated with Kaposi sarcoma-associated herpes virus/human herpes virus-8 (KSHV/HHV-8), arising as malignant effusions in body cavities. PEL cells do not harbor conventional genetic cancer mutations; however, their oncogenesis is mainly attributed to HHV-8 latent genes. Treatment strategies are inefficient resulting in poor prognosis of PEL patients, stressing the need for new effective therapy. ST1926 is a synthetic retinoid with favorable antitumor properties and no cross-resistance with the natural retinoid, all-trans retinoic acid. ST1926 has shown potent apoptotic activities on a variety of solid tumors and hematologic malignancies in in vitro and in vivo models. In the present study we elucidated the antitumor activities and underlying molecular mechanism of ST1926 using in vitro, ex vivo, and in vivo PEL preclinical models. ST1926, at sub-micromolar concentrations, displayed potent antiproliferative effects on PEL cell lines and malignant ascites. Furthermore, ST1926 treatment of PEL cells and ascites resulted in their accumulation in the sub- $\mathrm{G}_{1}$ region, $\mathrm{S}$ phase cell cycle arrest, early DNA damage, PARP cleavage and p53 activation including the upregulation of its target genes p21 and Bax. However, ST1926 did not significantly modulate HHV-8 latent viral transcripts. Importantly, ST1926 delayed formation of ascites and enhanced survival of PEL mice.
\end{abstract}

Correspondence to: Dr Raghida Abou Merhi, Genomic and Health/EDST-PRASE Laboratory, Faculty of Sciences, R. Hariri Campus, Lebanese University, P.O. Box 5, Hadath 1003, Lebanon E-mail: raboumerhi@ul.edu.lb

Dr Nadine Darwiche, Department of Biochemistry and Molecular Genetics, American University of Beirut, P.O. Box 11-0236, Riad El-Solh, Beirut 1107-2020, Lebanon

E-mail: nd03@aub.edu.lb

Key words: primary effusion lymphoma, ST1926, apoptosis, DNA damage, NOD/SCID mice
These results highlight the therapeutic potential of ST1926 in combination with drugs that target HHV-8 in PEL patients.

\section{Introduction}

Primary effusion lymphoma (PEL) is a rare aggressive nonHodgkin's B-cell lymphoma characteristically infected with Human Herpes Virus-8 (HHV-8) also known as Kaposi's sarcoma-associated herpesvirus (KSHV) (1-3). PEL is an acquired immunodeficiency syndrome (AIDS)-related cancer, accounting for $\sim 3 \%$ of human immunodeficiency virus (HIV)-associated lymphomas and can also occur in organ transplants of elderly patients $(4,5)$. PEL is an HHV-8-driven tumor and is uniquely manifested as a malignant effusion contained mostly in pleural, pericardial and peritoneal cavities, and commonly without any solid masses $(2,3,6)$. Occasionally, rare PEL cases can develop as a solid mass in lymph nodes and extra nodal variants known as extracavitary PEL (7-9). PEL cells are latently infected with $\mathrm{HHV}-8$ which persists as nuclear episomal DNA, with only a restricted subset of viral genes expressed, mostly contributing to transformation. These latent viral genes are LANA1, LANA2, vCyclin, vFlip, kaposin, microRNAs, and occasionally the viral interleukin-6 (vIL-6) (10-14).

Novel non-chemotherapeutic approaches for the treatment and prevention of PEL have been investigated and optimized $(4,6,15-17)$. We have shown that the combination arsenic trioxide (arsenic)/interferon- $\alpha$ (INF) induces apoptosis in PEL cells (18) and prolongs survival of PEL mice (19). Currently adopted PEL treatment strategies such as CHOP: cyclophosphamide, doxorubicin, vincristine and prednisone show dismal effect. Despite different present combination treatments, the prognosis of PEL patients is poor with a median survival of $<6$ months and very few long-term survivors $(6,13)$ which prompted the development of novel therapies.

Retinoids, natural and synthetic derivatives of vitamin A, are crucial regulators of cell growth, differentiation and apoptosis for a wide variety of malignancies $(20,21)$. Natural retinoids, such as all-trans retinoic acid (ATRA), are used in the clinic and have been tested in several clinical trials 
for hematological and solid malignancies (22-24). However, ATRA resistance and toxicity are frequently encountered in the cancer clinic $(25,26)$. Consequently, synthetic retinoids were developed to overcome ATRA resistance, namely ST1926 or adarotene, (2E)-3-[39-(1-adamantyl)-49hydroxy[1,19-biphenyl]-4-yl]-2-propenoic acid, an analog of CD437 6-[3-(1-adamantyl)-4-hydroxyphenyl]-2-naphthalene carboxylic acid $(27,28)$, that has shown potent apoptotic activities in several tumor models $(28,29)$. ST1926 has shown efficacy against solid tumor models derived from human ovarian carcinoma, lung carcinoma, rhabdomyosarcoma and melanoma at well-tolerated doses despite almost complete loss of ability to activate the retinoic acid receptor (RAR) signaling pathway $(28,30,31)$. ST1926 efficacy has also been demonstrated in in vitro and in vivo leukemia models for acute myeloid leukemia $(29,32)$, adult T-cell leukemia (33) and chronic myeloid leukemia (34) with minimal side-effects. ST1926 was shown to be a potent inducer of DNA damage and of genotoxic stress (35-37).

In the present study, we investigated the antitumor activities of ST1926 on PEL in vitro, ex vivo and in vivo models. We observed that ST1926 exhibited potent growth inhibitory effects at sub-micromolar $(\mu \mathrm{M})$ concentrations in HHV-8 positive PEL cells and corresponding malignant ascites. ST1926 induced apoptosis through early DNA damage and p53 activation. Importantly, ST1926 delayed ascites development and prolonged survival in PEL NOD/SCID mice. However, ST1926 did not regulate the expression of HHV-8 latent viral genes. Our results provide promising therapeutic use of ST1926 in combination with drugs that target HHV-8 in PEL patients.

\section{Materials and methods}

Drugs. ATRA was purchased from Sigma (St. Louis, MO, USA) and ST1926 was kindly provided by Biogem, Research Institute (Ariano Irpino, Italy). Retinoids were reconstituted, protected from light, in $0.1 \%$ dimethyl sulfoxide (DMSO) at a concentration of $10^{-2} \mathrm{M}$, stored at $-80^{\circ} \mathrm{C}$ and diluted to the final concentrations in complete culture medium. The final used DMSO concentrations never exceeded $0.1 \%$ which did not affect the growth of tested cells.

Cells. PEL cell lines BC1, BC3, BCBL1 and JSC1 are HHV- $8^{+}$ cells and a non-PEL cell line RAJI, as HHV-8- malignant B cell were obtained from DSMZ Co. (Leibniz-Institut, Braunschweig, Germany). Cells were cultured in RPMI-1640 medium (Lonza, Verviers, Belgium) supplemented with $10 \%$ (v/v) fetal bovine serum (FBS; Sigma), $100 \mathrm{U} / \mathrm{ml}$ penicillin/streptomycin (Lonza) at $37^{\circ} \mathrm{C}$ in a humidified atmosphere containing $5 \% \mathrm{CO}_{2}$.

Proliferation. Cell growth was assessed using the 3-(4,5-dimethylthiazol-2-yl)-2,5-diphenyltetrazolium bromide assay (MTT) (Sigma-Aldrich). PEL cells and malignant ascites were seeded at $2 \times 10^{5} / 0.1 \mathrm{ml}$ in triplicate in 96-well plates and treated using $0.1-3 \mu \mathrm{M}$ ST1926 or 1-10 $\mu \mathrm{M}$ ATRA for 3 days. Absorbance was measured at $595 \mathrm{~nm}$ [optical density (OD)] using an ELISA microplate reader. To test for the reversibility of ST1926 effect, malignant ascites were treated with 0.1-3 $\mu \mathrm{M}$
ST1926 for $24 \mathrm{~h}$, then washed and re-suspended in drug-free medium for 2 days. Cell growth was assessed by MTT (Sigma) added at $0.5 \mathrm{mg} / \mathrm{ml}$ to each well and incubated at $37^{\circ} \mathrm{C}$ for 3-4 h. Experiments were independently performed 3 times.

Cell cycle analysis. Control and treated PEL cells were treated for 24-48 h, collected, washed with ice-cold 1X phosphatebuffered saline (PBS) and fixed in $80 \%$ ice cold ethanol. Fixed cells were rinsed with PBS, incubated for $1 \mathrm{~h}$ in PBS containing $200 \mu \mathrm{g} / \mathrm{ml}$ RNase A (Roche Diagnostics,Mannheim, Germany), stained with propidium iodide (PI) $(50 \mu \mathrm{g} / \mathrm{ml})$ (Sigma), and analyzed by flow cytometry (BD FACSAria; BD Biosciences, San Jose, CA, USA) as previously described (18).

TUNEL assay. Control and treated PEL cell DNA fragmentation was detected by terminal deoxynucleotidyl transferase (TdT)-mediated dUTP nick-end labeling (TUNEL assay; Roche Diagnostics) and performed according to the manufacturer's recommendations. The incorporation of fluorescein-conjugated deoxy-UTP into nucleotide polymers was detected and quantified using flow cytometry (BD FACSAria). In total, 10,000 cells were acquired and analyzed using FACSDiva software (Becton-Dickinson, San Jose, CA, USA).

Immunoblot analysis. Cells were harvested at $4^{\circ} \mathrm{C}$ in lysis buffer consisting of $0.125 \mathrm{M}$ Tris- $\mathrm{HCl}$ (pH 6.8), $2 \%$ SDS, $2.5 \%$ $\beta$-mercaptoethanol, and $10 \%$ glycerol with protease and phosphatase inhibitors cocktails (Sigma). Proteins were loaded, separated onto an SDS polyacrylamide gel, subjected to electrophoresis, and transferred to nitrocellulose membranes (Bio-Rad, Hercules, CA, USA). After blocking the membranes in 5\% skimmed milk or BSA, the blots were incubated with specific antibodies overnight at $4^{\circ} \mathrm{C}$ : p53 (ab1011), p-p53 (ser15) (ab1431), p21 (ab109520), GAPDH (ab8245), p-ATM (S1981; ab81292) (Abcam Cambridge, MA, USA); PARP (sc-7150), $\gamma \mathrm{H} 2 \mathrm{AX}$ (sc-101696), ATM (sc-23921) (Santa Cruz Biotechnology, Santa Cruz, CA, USA); Bax (2774), bcl-2 (2872), Chk2 (2662), p-Chk2 (thr68, 2661) (Cell Signaling Technology, Inc., Danvers, MA, USA). Goat anti-rabbit secondary (ab6721) and rabbit anti-mouse antibodies (ab6728; Abcam)-conjugated to horseradish peroxidase were used for detection. Immunoreactive bands were visualized by enhanced chemiluminescence using the Clarity ${ }^{\mathrm{TM}}$ Western ECL Blotting Substrate (1705060; Bio-Rad).

RNA isolation and quantitative real-time PCR. Total RNA from $4 \times 10^{6}$ untreated and treated ascites-derived PEL cells was extracted by an RNeasy Mini kit (Qiagen, Gaithersburg, MD, USA) according to the manufacturer's instructions. First-strand cDNA was synthesized from $2 \mu \mathrm{g}$ of total RNA using RevertAid RT Reverse Transcription kit (Fermentas, Thermo Scientific, Waltham, MA, USA). cDNAs were amplified using the SYBR-Green Master Mix (iQ ${ }^{\mathrm{TM}} \mathrm{SYBR}^{\circledR}$-Green SuperMix), and CFX96 RT-PCR machine (both from Bio-Rad). HHV-8 primers for viral latent genes LANA1, $L A N A 2$ and GAPDH were designed by TIB MOLBIOL (Berlin, Germany) (19). Normalization of the transcript levels was carried out with the GAPDH housekeeping gene internal levels. Analysis was performed using the $\Delta \Delta \mathrm{Cq}$ method (38). 

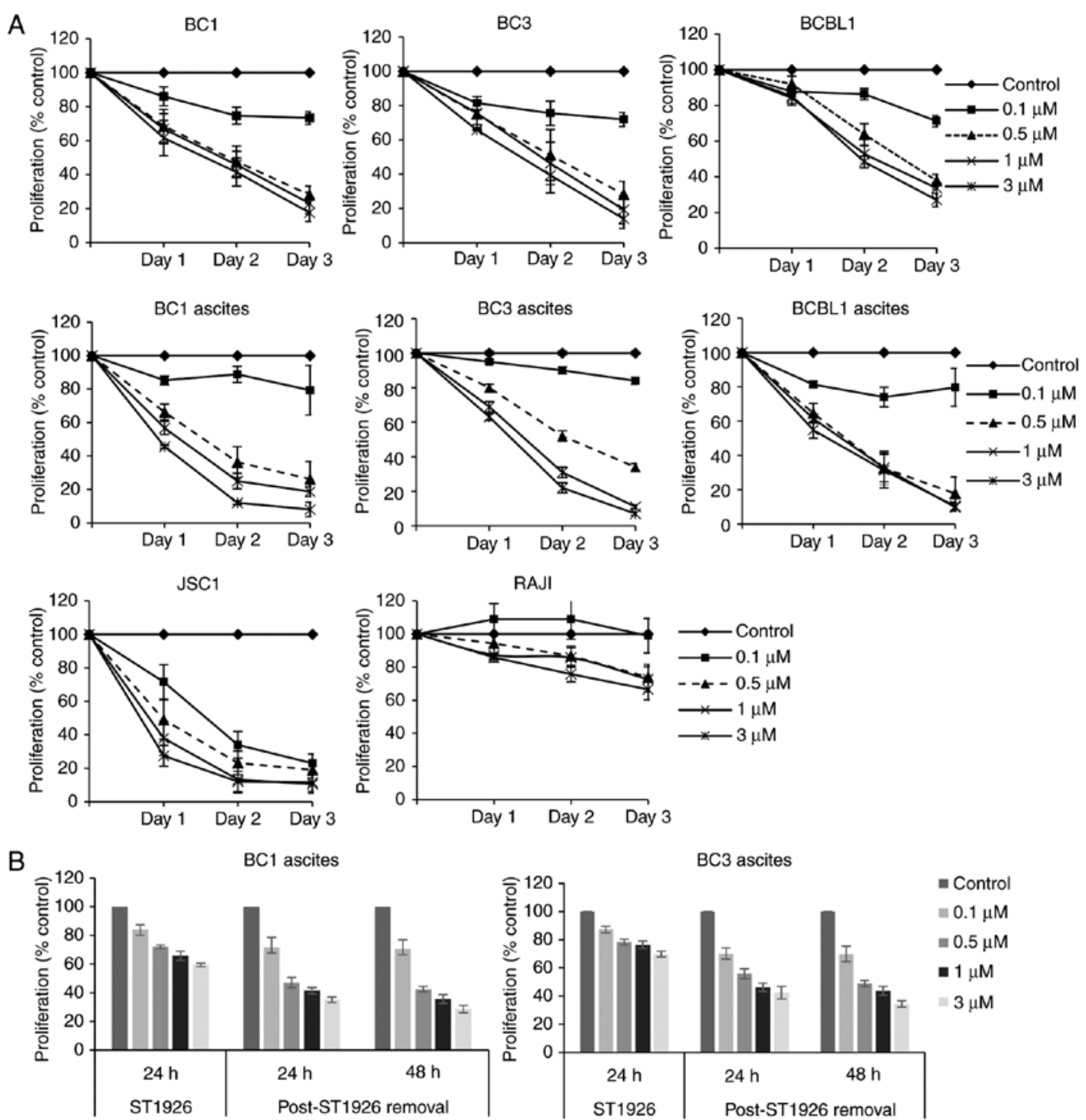

Figure 1. ST1926 irreversibly inhibits growth at submicromolar concentrations. (A) Antiproliferative effect of various concentration of ST1926 on PEL cells (BC1, BC3, BCBL1 and JSC1) and ascites (BC1, BC3 and BCBL1), and non-PEL cells (RAJI) using MTT assay for 3 days. (B) PEL ascites (BC1 and BC3) were treated with ST1926 for $24 \mathrm{~h}$, then, were cultured in 96-well plate in drug-free medium separately for 3 days. Cell growth was assayed in triplicate wells using the MTT cell proliferation assay. Results are expressed as percent of control, plotted as average \pm SE of 3 independent experiments.

Reaction conditions were as follow: $95^{\circ} \mathrm{C}$ for $10 \mathrm{~min}$, followed by 40 cycles of $95^{\circ} \mathrm{C}$ for $15 \mathrm{sec}, 55.5^{\circ} \mathrm{C}$ for $45 \mathrm{sec}$, and $72^{\circ} \mathrm{C}$ for $30 \mathrm{sec}$.

PEL xenograft mouse model, PEL ascites and treatment. To generate the PEL-like mouse model, BC1 and BC3 cells were propagated and maintained as per optimized procedures as previously described (19). Experiments were approved by the Institutional Animal Care and Use Committee of the American University of Beirut (IACUC approval \#14-3-292). Animals were monitored and euthanized when signs of distress appeared such as inability to move, to remain upright, clinical dehydration and weight loss of $15-20 \%$, lack of grooming and self-mutilation. Briefly, $3 \times 10^{6} \mathrm{PEL}$ cells were intraperitoneally (i.p.) injected into 5-6 weeks old NOD.CB17-Prkdcscid/J (NOD/SCID) female mice (The Jackson Laboratory, Bar Harbor, ME, USA). PEL cells showed efficient PEL engraftment as reflected by the development of malignant ascites within 3-4 weeks. For ex vivo treatment,
PEL ascites were recovered from the peritoneal cavities of mice, washed with PBS, cultured then treated with ATRA or ST1926 dissolved with 0.1\% DMSO at various doses ranging from 1-100 $\mu \mathrm{M}$, and $0.1-3 \mu \mathrm{M}$, respectively, at different time points ex vivo (24, 48 and 72 h). Control cells were incubated with maximum used amount of $0.1 \%$ DMSO.

Survival studies. For in vivo survival experiments, PEL NOD/SCID mice were i.p. treated with $15 \mathrm{mg} / \mathrm{kg}$ of ST1926 (resuspended in $100 \mu$ ldiluted in 1X PBS 10\% 1:1 cremophor/ethanol) 5 days/week for 5 weeks starting 2 days post-BC3 cell inoculation $\left(3 \times 10^{6} \mathrm{BC} 3\right.$ cells/mouse) $(\mathrm{n}=10)$. Untreated control PEL mice were injected only with vehicle (100 $\mu 1$ 1X PBS 10\% 1:1 cremophor/ethanol) and showed no signs of toxicity $(n=10)$. PEL NOD/SCID mouse phenotype was visually examined daily. Mice were weighed and peritoneal diameter (d) was measured once weekly with a caliper to evaluate ascites development. Peritoneal volume was calculated according to the formula: $v=4 / 3 \pi(d / 2)^{3}(39)$. 

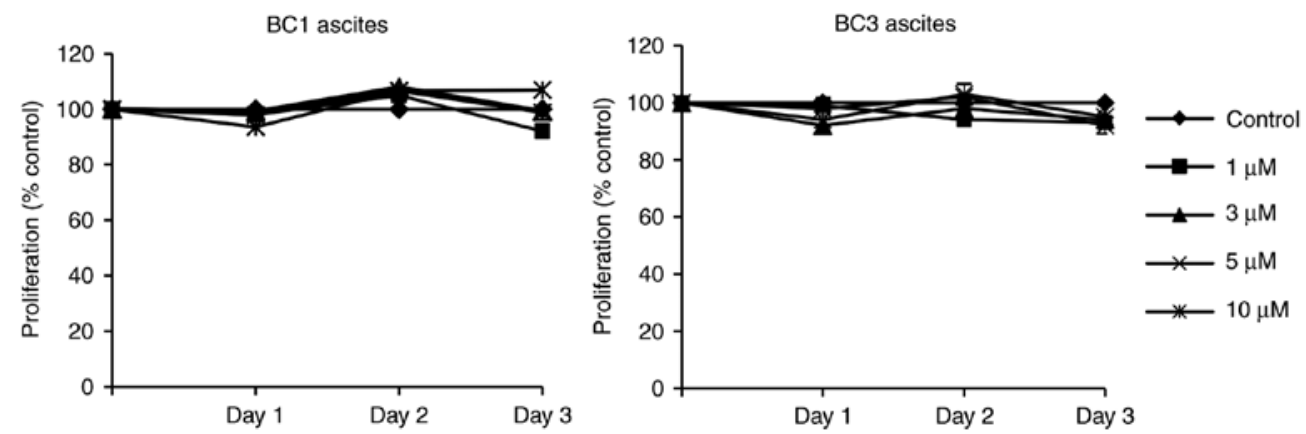

Figure 2. $\mathrm{BC} 1$ and $\mathrm{BC} 3$ ascites are resistant to ATRA. MTT assay results showing proliferation of $\mathrm{BC} 1$ and $\mathrm{BC} 3$ ascites after treatment with various concentrations of ATRA up to 3 days.
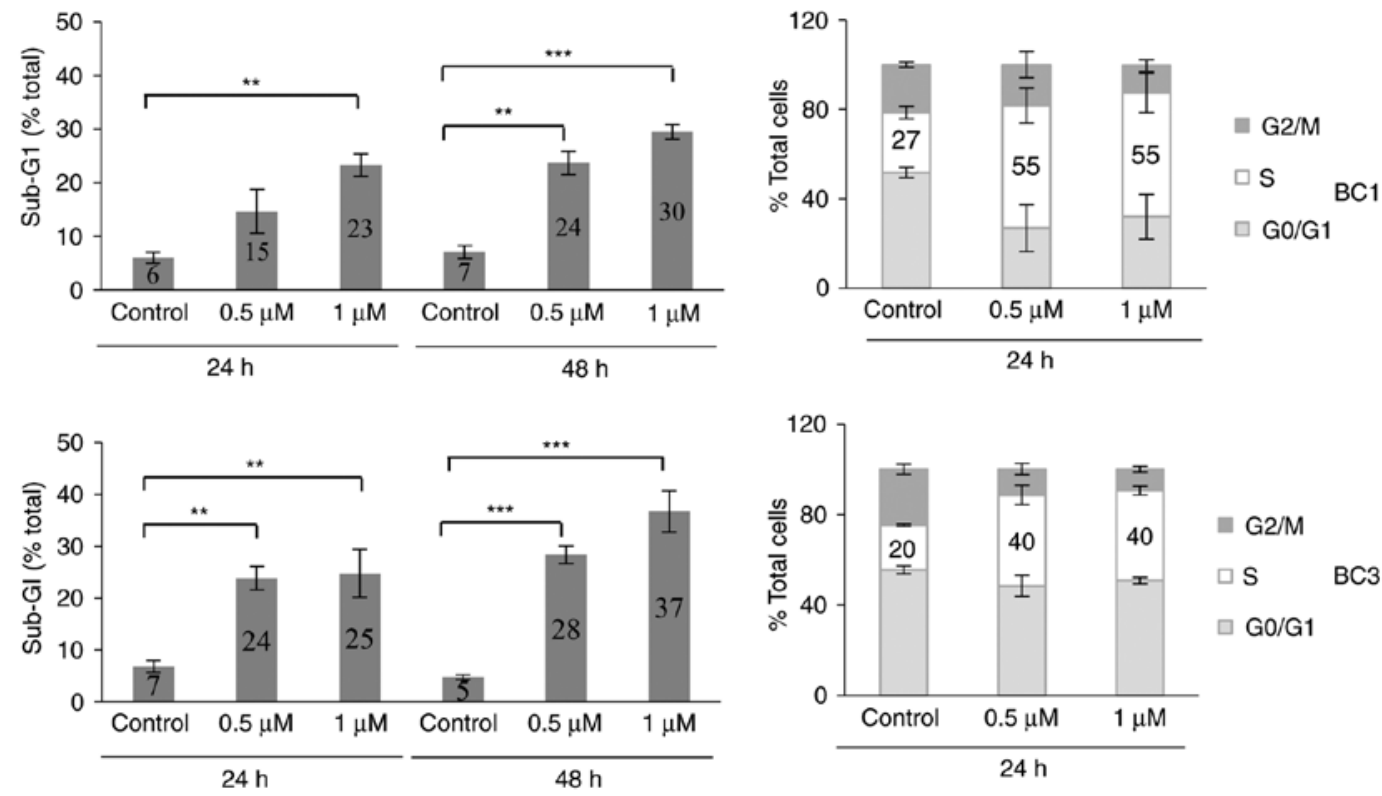

Figure 3. ST1926 induces sub-G1 and S phase arrest in PEL cells. BC1 and BC3 cell lines were treated with the indicated ST1926 concentration for $24 / 48 \mathrm{~h}$ and DNA was stained with PI for flow cytometric analysis of DNA content. The percentage of cells in each of the cell cycle phases was calculated using FacsDiva software. The sub-G1 population presumably represents apoptotic cells. Cycling cells, the sum of G1 +S + G2/M, are a percentage of non-apoptotic cells. Graphs are average of 3 independent experiments, each carried out in triplicate $\pm \mathrm{SE}\left({ }^{*} \mathrm{P}<0.05,{ }^{* *} \mathrm{P}<0.01,{ }^{* * *} \mathrm{P}<0.001\right.$ ANOVA Dunnett's).

Statistical analysis. Values are expressed as mean \pm SE. Differences between control and treatments groups were tested for statistical significance by one-way ANOVA with Dunnett's post test or t-test and Mann-Whitney U test using GraphPad Prism 5 Software (GraphPad, San Diego, CA, USA), as appropriate. A confidence level of $\mathrm{P}<0.05$ was chosen as statistically significant. Each experiment was performed independently at least 3 times unless otherwise indicated. Survival curves were calculated according to the method of Kaplan and Meier using GraphPad Prism 5.

\section{Results}

ST1926 induces irreversible growth inhibition in PEL cells at sub-micromolar concentrations. We first tested the effects of ST1926 on the growth of PEL cells. We used a variety of PEL cell lines (BC1, BC3, BCBL1 and JSC1), and ascites-derived PEL cells from $\mathrm{BC} 1, \mathrm{BC} 3$ and $\mathrm{BCBL} 1$ as well as Burkitts lymphoma non-PEL cells (RAJI). We observed that ST1926 inhibited cell proliferation of all tested PEL cells in vitro and ex vivo (Fig. 1A). Pharmacologically achievable sub- $\mu \mathrm{M}$ concentrations of ST1926 $(31,40)$ showed a growth suppressive effect and a concentration of $0.5 \mu \mathrm{M}$ caused pronounced growth reduction in all tested PEL cells ranging from $40-80 \%$ after $48 \mathrm{~h}$ of treatment. However, non-PEL RAJI cells were less sensitive to ST1926, with $<20 \%$ growth inhibition upon treatment with $0.5 \mu \mathrm{M}$ concentrations for $48 \mathrm{~h}$ (Fig. 1A). In general, $0.1 \mu \mathrm{M} \mathrm{ST} 1926$ showed minimal effect on the growth of PEL cells except in JSC1 cells where it caused an approximate $70 \%$ growth inhibition by $48 \mathrm{~h}$. To test whether ST1926-induced growth inhibition was irreversible, $\mathrm{BC} 1$ and BC3 ascites were treated with different ST1926 concentrations $(0.1-3 \mu \mathrm{M})$ for $24 \mathrm{~h}$, and then resuspended in drug-free media for an additional $48 \mathrm{~h}$. We observed that ST1926 antiproliferative effect was irreversible at all tested concentrations in both cell lines (Fig. 1B). However, PEL ascites were highly resistant to the natural retinoid, ATRA, up to $10 \mu \mathrm{M}$ concentrations (Fig. 2). For subsequent mechanistic studies, we selected $\mathrm{BC} 1$ and $\mathrm{BC} 3$ cell lines or ascites as representative of PEL in vitro and ex vivo models. 

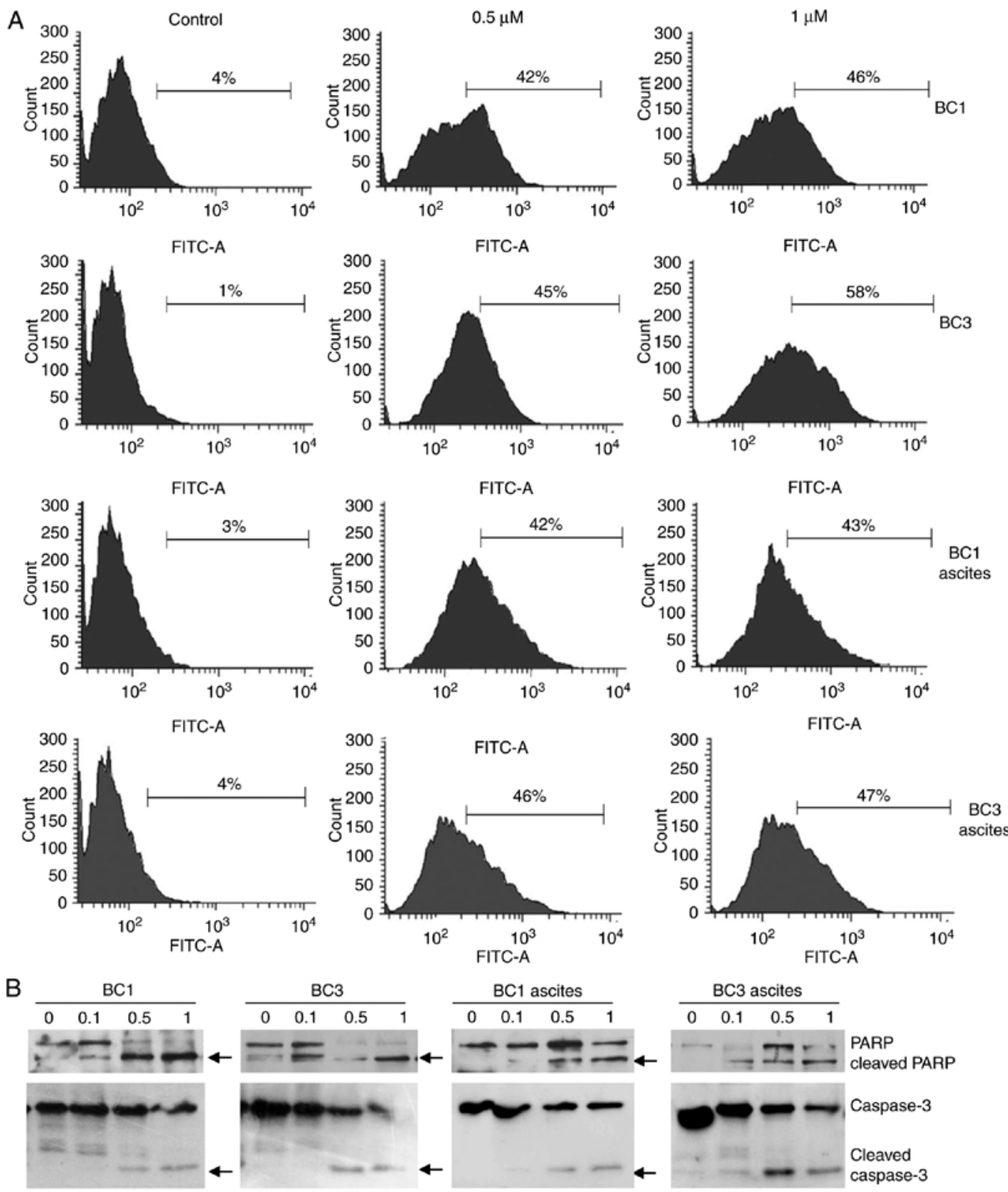

Figure 4. ST1926 induces apoptosis in PEL cells. (A) TUNEL assay of BC1 and BC3 cells and ascites treated with $0.1 \%$ DMSO or 0.5 and $1 \mu \mathrm{M} \mathrm{ST1926}$ for $48 \mathrm{~h}$. (B) Total SDS protein lysates (60 $\mu \mathrm{g} / \mathrm{lane})$ of PEL cells and ascites were prepared and immunoblotted against PARP and caspase 3 . Arrows indicate cleaved proteins. TUNEL and western blot results are representative of 2 independent experiments.

ST1926 causes $S$ phase arrest and apoptosis in PEL cells. To investigate the mechanism of ST1926-induced growth suppression of PEL cells, we performed cell cycle analysis of PEL cells using flow cytometric analysis of DNA content. BC1 and $\mathrm{BC} 3$ cells were treated with 0.5 and $1 \mu \mathrm{M} \mathrm{ST} 1926$ for up to $48 \mathrm{~h}$. These concentrations resulted in major disruption of the cell cycle causing a significant accumulation of cells in the sub-G1 region in both $\mathrm{BC} 1$ and $\mathrm{BC} 3$-treated cells (Fig. 3) as evident in representative histograms (data not shown). Furthermore, ST1926 induced a prominent S phase arrest after $24 \mathrm{~h}$ of treatment where $0.5 \mu \mathrm{M}$ concentrations resulted in doubling of cells in the S phase from 27-55 and 20-40\% of $\mathrm{BC} 1$ and $\mathrm{BC} 3$ cells, respectively (Fig. 3).

To confirm whether treated PEL cells that accumulated in the sub-G1 region of the cell cycle were apoptotic, TUNEL assay was carried out. Treatment of $\mathrm{BC} 1$ and $\mathrm{BC} 3$ cells and corresponding ascites with $0.5 \mu \mathrm{M} \mathrm{ST} 1926$ resulted in a substantial increase in the percentage of TUNEL-positive cells from $1-4 \%$ in control cells to as high as $42-58 \%$ in treated cells (Fig. 4A). Furthermore, to test whether caspases were activated in ST1926-induced apoptosis, PEL cells and ascites (BC1 and BC3) were treated with 0.1-1 $\mu \mathrm{M} \mathrm{ST} 1926$ up to $48 \mathrm{~h}$. Western blot analysis revealed that ST1926induced apoptosis was associated with PARP and caspase 3 cleavage in all tested cells at ST1926 concentrations as low as $0.5 \mu \mathrm{M}$ (Fig. 4B).

To assess the involvement of key players in the observed ST1926 apoptotic effect, p53 protein levels and its phosphorylated form were measured in $\mathrm{BC} 1$ and $\mathrm{BC} 3$ cells and ascites with $0.1-1 \mu \mathrm{M}$ ST1926 $48 \mathrm{~h}$ post-treatment. Low sub- $\mu \mathrm{M}$ concentrations of ST1926 induced a substantial phosphorylation of p53 and upregulation of total p53 proteins in tested 

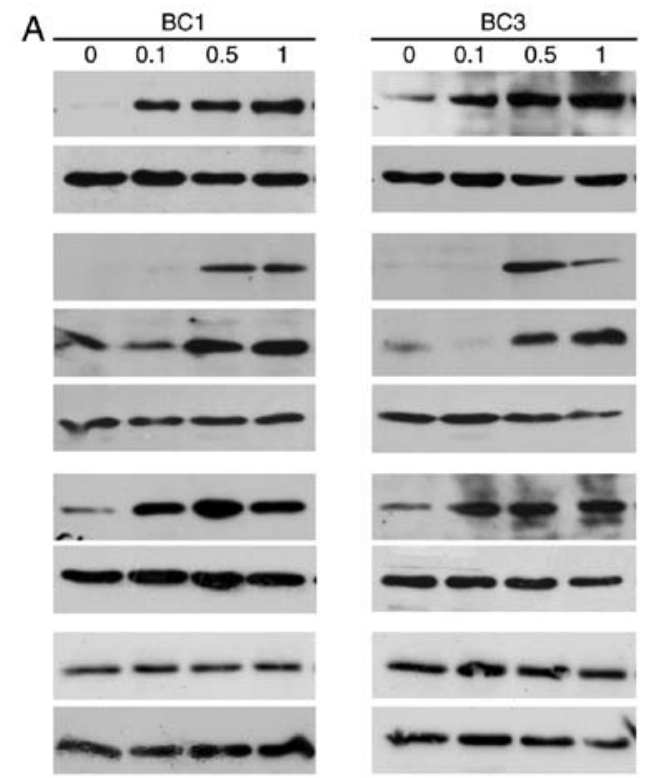

B

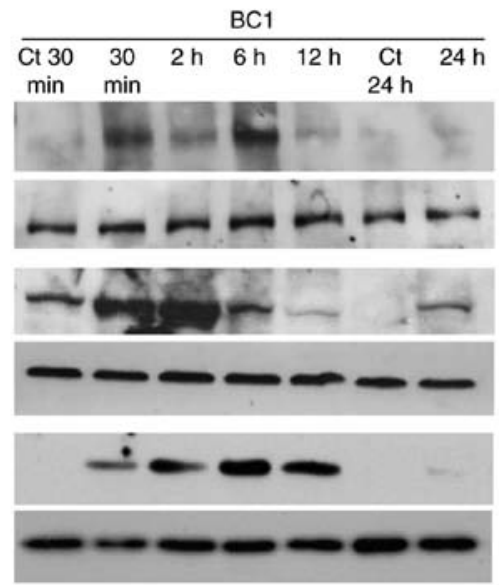

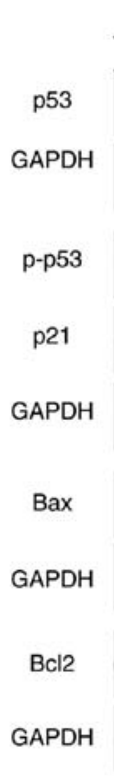
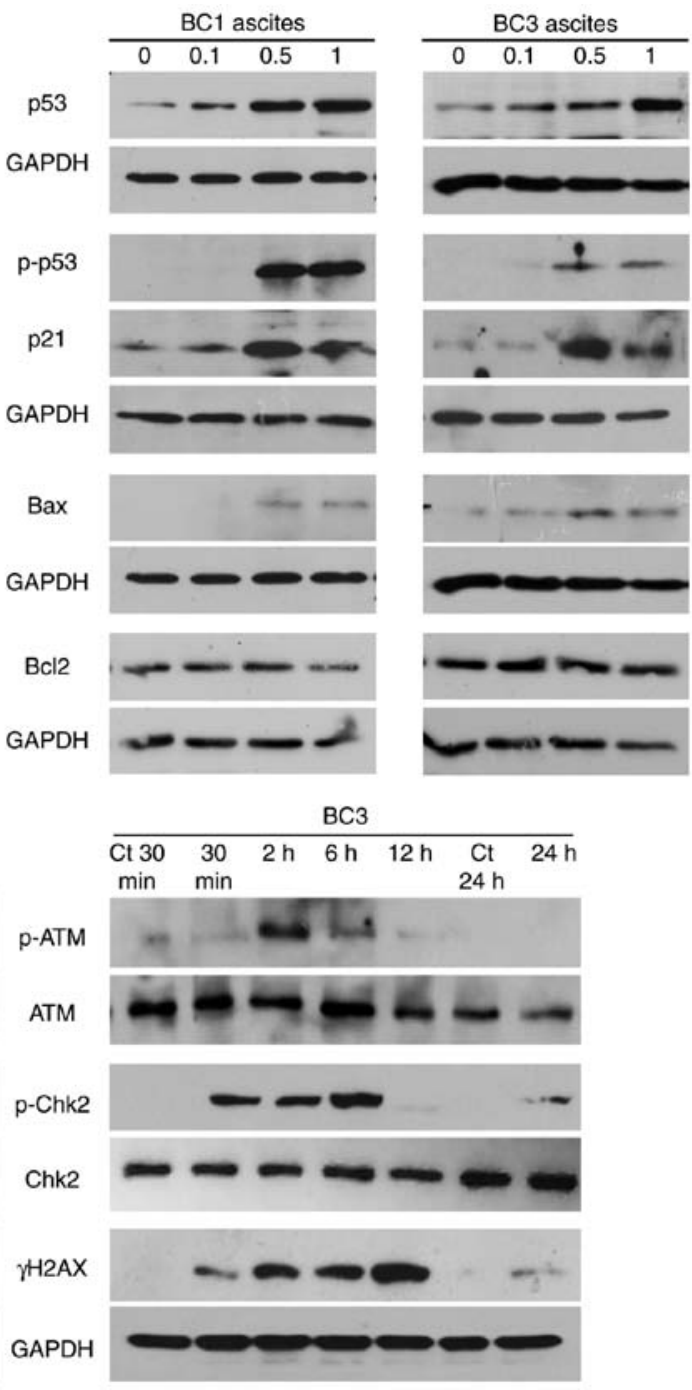

Figure 5. ST1926 causes induction of apoptosis related proteins and DNA damage response (DDR) in PEL cells. (A) BC1 and BC3 cells and ascites were treated with $0.1 \%$ DMSO or 0.1-1 $\mu \mathrm{M}$ of ST1926 for 48 h. Protein extracts of treated and control cells were immunoblotted against p53, p-p53, p21, Bax, Bcl2. (B) BC1 and BC3 cell lines were treated with $0.1 \%$ DMSO or $1 \mu \mathrm{M} \mathrm{ST} 1926$ and immunoblotted against $\gamma$-H2AX, p-ATM, Chk2 and p-Chk2 at the indicated treatment times. Results are representative of at least 2 independent experiments. GAPDH antibody was used to ensure equal protein loading for all blots.

cells (Fig. 5A). To provide more evidence on p53 activation, we measured the expression of the p53 target genes, p21, Bax and $B c l 2$ (41). ST1926 treatment resulted in increased expression of p21 and Bax protein levels in all tested cells, while no changes were observed in Bcl2 (Fig. 5A).

ST1926 induces early DNA damage response. The antitumor activity of ST1926 in different types of tumors has been associated with its capacity to induce early genotoxic stress and to cause S phase-specific DNA double-strand breaks (DSBs) which is followed by phosphorylation of the histone $\mathrm{H} 2 \mathrm{AX}$ to $\gamma \mathrm{H} 2 \mathrm{AX}(33,35,42-44)$. Inhibition of DNA damage response pathway (DDR) results in ST1926 resistance in tumor cells (35). Therefore, the present study also investigated the action of ST1926 on the DDR in PEL cells. Several DDR markers and players, namely $\gamma \mathrm{H} 2 \mathrm{AX}, \mathrm{p}-\mathrm{Chk} 2$ and p-ATM levels, were detected as early as 30 min post-ST1926 treatment (Fig. 5B). Upregulation of $\gamma \mathrm{H} 2 \mathrm{AX}$ proteins was transiently detected from 30 min until 12 h-post treatment indicating that ST1926 elicited a potent early DNA damaging effect in PEL cells. In addition, activated p-Chk2 and p-ATM were observed as early as $30 \mathrm{~min}$ until $6 \mathrm{~h}$ post-ST1926 treatment without detectable changes in their total protein levels (Fig. 5B).

ST1926 has no effect on HHV-8 viral latent transcripts. It is well established that the expression of HHV-8 latency genes, specifically LANA1, is crucial for maintaining HHV-8 infection, and leads to inhibition of RB1 thus apoptosis in infected cells $(13,45,46)$. In addition, LANA2 which is essential for PEL cell survival contributes to HHV-8-driven oncogenesis (47). To assess whether ST1926 treatment modulates HHV-8 latent gene expression, LANA1 and LANA2 transcript levels weremeasured in ascites-derived from BC1 and BC3 cells. Our results show no significant variations in LANA1 and LANA2 transcript levels in BC1 and BC3 ascites at $24 \mathrm{~h}$ post-ST1926 treatment at $0.5 \mu \mathrm{M}(\mathrm{P}>0.05)$ (Fig. 6).

ST1926 delays ascites development and extends PEL mouse survival. The potent proapoptotic activities in PEL in vitro and ex vivo models, suggest that ST1926 could be a promising 

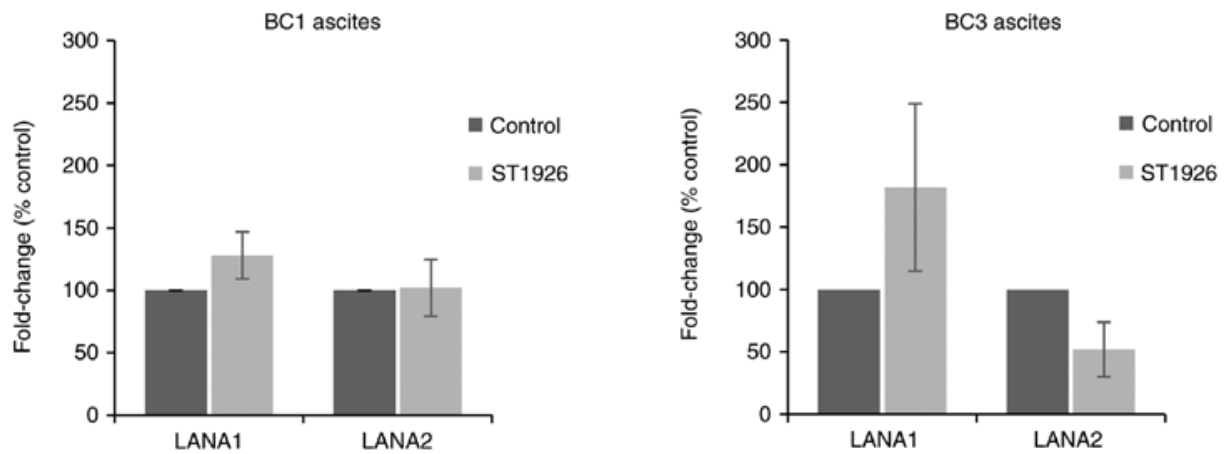

Figure 6. ST1926 effect does not modulate the expression of HHV-8 latent LANA1 and LANA2 transcripts. RNA was isolated from BC1 and BC3 ascites treated with $0.5 \mu \mathrm{M} \mathrm{ST} 1926$ or $0.1 \%$ DMSO (control cells) up to $24 \mathrm{~h}$ and real-time PCR was performed as previously described. Data are expressed as the percent fold-change relative to the corresponding mRNA levels in the untreated control (0.1\% DMSO) set to $100 \%$. Relative expression levels of the amount of LANA1 and LANA2 transcripts were calculated to the amount of GAPDH RNA used as internal control. The averages of the normalized control values of GAPDH for each sample were used to determine the relative changes in gene expression of the KSHV latency transcripts by the comparative CT method $(\Delta \Delta \mathrm{Cq})$. Error bars represent the $\pm \mathrm{SE}$ of 3 independent experiments (Wilcoxon test; $\mathrm{P}>0.05$ ).

A

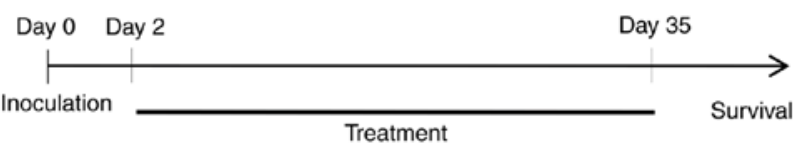

$\mathrm{C}$

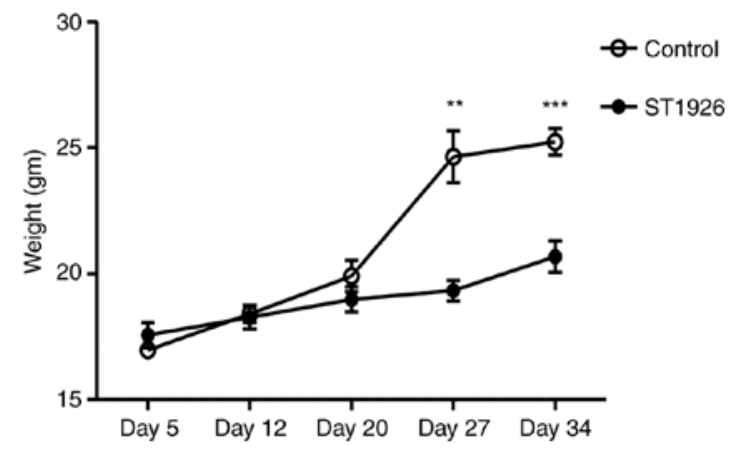

B

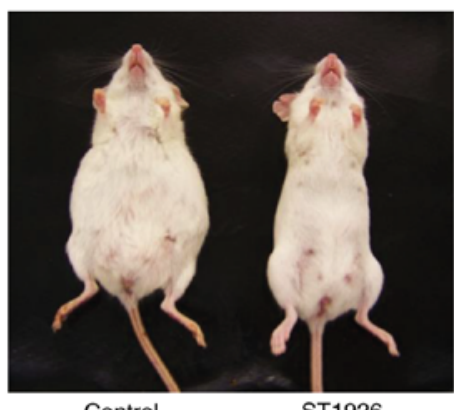

Control

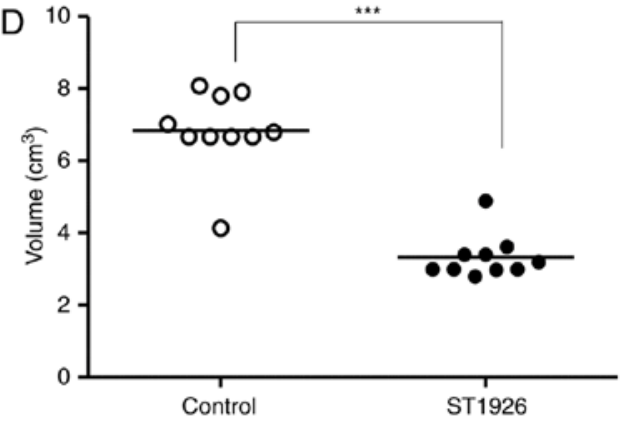

$\mathrm{E}$

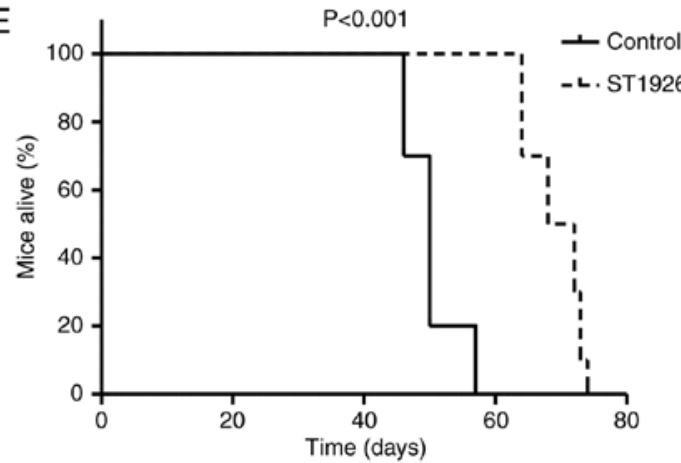

Figure 7. ST1926 delays ascites formation and improves survival in PEL mouse model. (A) Schematic outline of the in vivo experiment of PEL NOD/SCID mice treated with ST1926 at 2 days post PEL cell inoculation. (B) Image of untreated and treated PEL mouse model after 5 weeks of daily i.p injection with $15 \mathrm{mg} / \mathrm{kg}$ ST1926. Measurement of weekly body weight change (C) and abdominal volume (D) at the last dose (day 35) of control and ST1926-treated PEL mice $\left(\mathrm{n}=10\right.$ each). (E) Kaplan-Meier plot of survival is presented and log-rank for statistical analysis $\left({ }^{* * * *} \mathrm{P}<0.001\right)$.

therapeutic approach in in vivo PEL models. Therefore, we evaluated the activities of ST1926 using an established PEL
NOD/SCID model. BC3 cells were intraperitoneally (i.p.) inoculated into NOD/SCID mice. Two days after cell injections, 
animals were randomly assigned to control group $(\mathrm{n}=10)$ and $15 \mathrm{mg} / \mathrm{kg}$ ST1926 treated daily for 5 weeks $(\mathrm{n}=10)$ (Fig. 7A). At day 35 post-inoculation (last dose), control mice presented with a massive abdominal distension (Fig. 7B), due to ascites formation with a significant concomitant increase in the mean abdominal weight (Fig. 7C) and volume (Fig. 7D) compared to ST1926-treated mice which appeared normal $(\mathrm{P}<0.001)$. The increase of body weight in BC3-inoculated mice was significantly reduced upon ST1926 treatment in a time-dependent manner $(\mathrm{P}<0.001)$ (Fig. 7C). Kaplan-Meier analysis indicated that ST1926 treatment conferred a significant survival advantage in PEL xenografted mice with a median survival time of 70 days in treated vs. 50 days in control animals $(\mathrm{P}<0.001)$ (Fig. 7E).

\section{Discussion}

In the present study, we assessed the antitumor activities of ST1926 on PEL using in vitro, ex vivo and in vivo models and investigated the underlying molecular mechanism. We showed that sub $-\mu \mathrm{M}$ concentrations of ST1926 irreversibly inhibited growth and induced apoptosis of different PEL cell lines and ascites. These results are in accordance with previous studies in other hematological malignancies such as in acute myeloid leukemia (29), adult-T cell leukemia/lymphoma (33) and chronic myeloid leukemia (34).

The natural retinoid ATRA is used in the cancer clinic in particular, for the treatment of acute promyelocytic leukemia (48). Nevertheless, its clinical efficacy is hampered by adverse side-effects and tumor resistance which prompted the emergence of new synthetic retinoids such as fenritinide (HPR) and ST1926 among others. All tested PEL cells exhibited resistance to ATRA and an increased specific and notable sensitivity to ST1926 vs. HPR (data not shown).

Apoptosis is an essential programmed molecular process which eliminates abnormal cells including neoplastic and hyperplastic ones and protects against cancer progression (49). Inducing cell death in cancer cells is a key strategy in cancer treatment and studies have shown that ST1926 induces apoptosis in a variety of human cancer models as observed in our studies. Indeed, sub- $\mu \mathrm{M}$ concentrations of ST1926 potently induced apoptosis in PEL cells and malignant ascites shown by a variety of assays including caspase activation and modulation of apoptotic players. In PEL, ST1926 activated p53 into its phosphorylated form, leading to subsequent upregulation in its transcriptional targets, Bax and p21. This is in agreement with previous studies showing that ST1926 functions in a p53-dependent manner $(34,50)$. However, other studies reported that ST1926 can function also in a p53-independent manner $(30,44)$ which may explain the significant growth inhibition in BCBL1 cells harboring a mutant p53 (51).

Drugs that halt DNA replication, such as cisplatin, camptothecin, etoposide and doxorubincin, are currently the most used anticancer agents in the cancer clinic $(52,53)$. In the present study, we observed an early induction of $\gamma \mathrm{H} 2 \mathrm{AX}$, a key marker of DNA damage. These results are in accordance with previous ones showing that ST1926 elicits DNA damage, genotoxic stress and $\mathrm{S}$ phase arrest in PEL cells $(31,33,34,36,43,44)$. We have observed that the DNA damage occurred very early and thus, was not secondary to apoptosis. ST1926 was shown to induce substantial DDR leading consequently to $\mathrm{S}$ phase arrest, with phosphorylation of ATM, and its substrates, H2AX and the checkpoint effector protein Chk2 kinase $(54,55)$ at early times of PEL treatment. It is of interest to note that ST1926-induced cell death and DDR were observed in PEL cells at sub- $\mu \mathrm{M}$ concentrations as pharmacologically achievable $\mu \mathrm{M}$ concentrations of ST1926 are short-lived in humans (40) and in mice (31).

Due to the low incidence of PEL, optimization of a therapeutic approach remains limited. ST1926 showed a promising effect in various solid and liquid tumor models as well as in our PEL xenograft model. ST1926 treatment delayed ascites formation in PEL NOD/SCID mice. Importantly, ST1926 significantly prolonged PEL NOD/SCID mouse survival, however, the animals developed ascites after treatment cessation. Further investigations are required to optimize ST1926 treatment regimen in PEL.

Notably, HHV-8 latent viral protein being involved in PEL oncogenesis, HHV-8-positive PEL cells were particularly sensitive to ST1926 compared to HHV-8-negative RAJI lymphoma cells. Our previous studies validated that arsenic/INF treatment targets viral latent transcripts (19), thus, we investigated whether ST1926 specifically modulates LANA1 and LANA2 transcripts. In the present study, ST1926 did not significantly affect HHV-8 latent viral genes. A plausible explanation may be that ST1926 only targets cellular pathways regardless of the virus and RAJI cells resistance is yet to be explored.

Chemotherapeutic drugs are mostly effective when given in combination treatment. We previously reported the efficacy of arsenic/INF on PEL both in vitro and in vivo $(18,19)$. Thus, the combination of ST1926 with other drugs mainly anti-viral such as nucleoside inhibitors cidofovir (56), plant-derived such as angelicin which targets lytic replication (57) or drugs that are known to target HHV-8 genes essential for PEL cell survival such as azidothymidine which inhibits LANA2/vIRF3 functions in PEL (58), represents favorable therapeutic strategies. In addition, other drugs as well can be combined with ST1926 such as the immunomodulatory lenalidomide (17). The rationale for combination therapies is to use drugs that target different pathways at lower concentrations, thereby, decreasing the likelihood of cancer resistance and toxicity in PEL treatment.

\section{Acknowledgements}

The authors thank the EDST/PRASE platform at the Lebanese University (Lebanon). They acknowledge the core laboratories at the American University of Beirut (Lebanon). The present study was supported by grants from the Lebanese University and the Lebanese National Council for Scientific Research (LNCSR).

\section{References}

1. Cesarman E, Chang Y, Moore PS, Said JW and Knowles DM: Kaposi's sarcoma-associated herpesvirus-like DNA sequences in AIDS-related body-cavity-based lymphomas. N Engl J Med 332: 1186-1191, 1995.

2. Chen YB, Rahemtullah A and Hochberg E: Primary effusion lymphoma. Oncologist 12: 569-576, 2007.

3. Patel S and Xiao P: Primary effusion lymphoma. Arch Pathol Lab Med 137: 1152-1154, 2013. 
4. Boulanger E, Meignin V and Oksenhendler E: Bortezomib (PS-341) in patients with human herpesvirus 8-associated primary effusion lymphoma. Br J Haematol 141: 559-561, 2008.

5. Jones D, Ballestas ME, Kaye KM, Gulizia JM, Winters GL, Fletcher J, Scadden DT and Aster JC: Primary-effusion lymphoma and Kaposi's sarcoma in a cardiac-transplant recipient. N Engl J Med 339: 444-449, 1998.

6. Okada S, Goto H and Yotsumoto M: Current status of treatment for primary effusion lymphoma. Intractable Rare Dis Res 3: 65-74, 2014.

7. Metcalf RA, Wang L, Deos PH, Chock E, Warnke RA and Natkunam Y: Extracavity primary effusion lymphoma presenting in a lymph node without lymphomatous effusions. Hum Pathol Case Rep 2: 36-41, 2015.

8. Pan ZG, Zhang QY, Lu ZB, Quinto T, Rozenvald IB, Liu LT, Wilson D, Reddy V, Huang Q, Wang HY, et al: Extracavitary KSHV-associated large B-Cell lymphoma: A distinct entity or a subtype of primary effusion lymphoma? Study of 9 cases and review of an additional 43 cases. Am J Surg Pathol 36: 1129-1140, 2012.

9. Carbone A, Gloghini A, Vaccher E, Cerri M, Gaidano G, Dalla-Favera R and Tirelli U: Kaposi's sarcoma-associated herpesvirus/human herpesvirus type 8-positive solid lymphomas: A tissue-based variant of primary effusion lymphoma. J Mol Diagn 7: 17-27, 2005.

10. Rivas C, Thlick A-E, Parravicini C, Moore PS and Chang Y: Kaposi's sarcoma-associated herpesvirus LANA2 is a B-cellspecific latent viral protein that inhibits p53. J Virol 75: 429-438, 2001.

11. Fakhari FD, Jeong JH, Kanan Y and Dittmer DP: The latencyassociated nuclear antigen of Kaposi sarcoma-associated herpesvirus induces B cell hyperplasia and lymphoma. J Clin Invest 116: 735-742, 2006.

12. Wen KW and Damania B: Kaposi sarcoma-associated herpesvirus (KSHV): Molecular biology and oncogenesis. Cancer Lett 289: 140-150, 2010.

13. Carbone A, Cesarman E, Spina M, Gloghini A and Schulz TF: HIV-associated lymphomas and gamma-herpesviruses. Blood 113: 1213-1224, 2009.

14. Goncalves PH, Ziegelbauer J, Uldrick TS and Yarchoan R: Kaposi sarcoma herpesvirus-associated cancers and related diseases. Curr Opin HIV AIDS 12: 47-56, 2017.

15. Hussain AR, Ahmed M, Ahmed S, Manogaran P, Platanias LC, Alvi SN, Al-Kuraya KS and Uddin S: Thymoquinone suppresses growth and induces apoptosis via generation of reactive oxygen species in primary effusion lymphoma. Free Radic Biol Med 50 978-987, 2011.

16. Bhatt S, Ashlock BM, Toomey NL, Diaz LA, Mesri EA, Lossos IS and Ramos JC: Efficacious proteasome/HDAC inhibitor combination therapy for primary effusion lymphoma. J Clin Invest 123 : 2616-2628, 2013.

17. Gopalakrishnan R, Matta H, Tolani B, Triche T Jr and Chaudhary PM: Immunomodulatory drugs target IKZF1IRF4-MYC axis in primary effusion lymphoma in a cereblon-dependent manner and display synergistic cytotoxicity with BRD4 inhibitors. Oncogene 35: 1797-1810, 2016.

18. Abou-Merhi R, Khoriaty R, Arnoult D, El Hajj H, Dbouk H, Munier S, El-Sabban ME, Hermine O, Gessain A, de Thé H, et al: PS-341 or a combination of arsenic trioxide and interferonalpha inhibit growth and induce caspase-dependent apoptosis in $\mathrm{KSHV} / \mathrm{HHV}$-8-infected primary effusion lymphoma cells. Leukemia 21: 1792-1801, 2007

19. El Hajj H, Ali J, Ghantous A, Hodroj D, Daher A, Zibara K, Journo C, Otrock Z, Zaatari G, Mahieux R, et al: Combination of arsenic and interferon- $\alpha$ inhibits expression of KSHV latent transcripts and synergistically improves survival of mice with primary effusion lymphomas. PLoS One 8: e79474, 2013.

20. Lippman SM and Lotan R: Advances in the development of retinoids as chemopreventive agents. J Nutr 130 (Suppl 2S): 479S-482S, 2000

21. Gudas LJ: Emerging roles for retinoids in regeneration and differentiation in normal and disease states. Biochim Biophys Acta 1821: 213-221, 2012.

22. Tan X, Sande JL, Pufnock JS, Blattman JN and Greenberg PD Retinoic acid as a vaccine adjuvant enhances $\mathrm{CD}^{+} \mathrm{T}$ cell response and mucosal protection from viral challenge. J Virol 85 : $8316-8327,2011$
23. Schlenk RF, Lübbert M, Benner A, Lamparter A, Krauter J, Herr W, Martin H, Salih HR, Kündgen A, Horst HA, et al; German-Austrian Acute Myeloid Leukemia Study Group: All-trans retinoic acid as adjunct to intensive treatment in younger adult patients with acute myeloid leukemia: Results of the randomized AMLSG 07-04 study. Ann Hematol 95: 1931-1942, 2016.

24. Schenk T, Stengel S and Zelent A: Unlocking the potential of retinoic acid in anticancer therapy. Br J Cancer 111: 2039-2045, 2014.

25. de Thé H: Altered retinoic acid receptors. FASEB J 10: 955-960, 1996.

26. Fontana JA and Rishi AK: Classical and novel retinoids: Their targets in cancer therapy. Leukemia 16: 463-472, 2002.

27. Parrella E, Giannì M, Fratelli M, Barzago MM, Raska I Jr, Diomede L, Kurosaki M, Pisano C, Carminati P, Merlini L, et al: Antitumor activity of the retinoid-related molecules (E)-3-(4'-hydroxy-3'-adamantylbiphenyl-4-yl)acrylic acid (ST1926) and 6-[3-(1-adamantyl)-4-hydroxyphenyl]-2-naphthalene carboxylic acid (CD437) in F9 teratocarcinoma: Role of retinoic acid receptor gamma and retinoid-independent pathways. Mol Pharmacol 70: 909-924, 2006.

28. Cincinelli R, Dallavalle S, Merlini L, Penco S, Pisano C, Carminati P, Giannini G, Vesci L, Gaetano C, Illy B, et al: A novel atypical retinoid endowed with proapoptotic and antitumor activity. J Med Chem 46: 909-912, 2003.

29. Garattini E, Gianni M and Terao M: Retinoid related molecules an emerging class of apoptotic agents with promising therapeutic potential in oncology: Pharmacological activity and mechanisms of action. Curr Pharm Des 10: 433-448, 2004.

30. Zuco V, Zanchi C, Cassinelli G, Lanzi C, Supino R, Pisano C, Zanier R, Giordano V, Garattini E and Zunino F: Induction of apoptosis and stress response in ovarian carcinoma cell lines treated with ST1926, an atypical retinoid. Cell Death Differ 11: 280-289, 2004

31. Basma H, Ghayad SE, Rammal G, Mancinelli A, Harajly M, Ghamloush F, Dweik L, El-Eit R, Zalzali H, Rabeh W, et al: The synthetic retinoid ST1926 as a novel therapeutic agent in rhabdomyosarcoma. Int J Cancer 138: 1528-1537, 2016.

32. Garattini E, Parrella E, Diomede L, Gianni' M, Kalac Y, Merlini L, Simoni D, Zanier R, Ferrara FF, Chiarucci I, et al: ST1926, a novel and orally active retinoid-related molecule inducing apoptosis in myeloid leukemia cells: Modulation of intracellular calcium homeostasis. Blood 103: 194-207, 2004.

33. El Hajj H, Khalil B, Ghandour B, Nasr R, Shahine S, Ghantous A, Abdel-Samad R, Sinjab A, Hasegawa H, Jabbour M, et al: Preclinical efficacy of the synthetic retinoid ST1926 for treating adult T-cell leukemia/lymphoma. Blood 124: 2072-2080, 2014.

34. Nasr RR, Hmadi RA, El-Eit RM, Iskandarani AN, Jabbour MN, Zaatari GS, Mahon FX, Pisano CC and Darwiche ND: ST1926, an orally active synthetic retinoid, induces apoptosis in chronic myeloid leukemia cells and prolongs survival in a murine model. Int J Cancer 137: 698-709, 2015.

35. Zuco V, Zanchi C, Lanzi C, Beretta GL, Supino R, Pisano C, Barbarino M, Zanier R, Bucci F, Aulicino C, et al: Development of resistance to the atypical retinoid, ST1926, in the lung carcinoma cell line $\mathrm{H} 460$ is associated with reduced formation of DNA strand breaks and a defective DNA damage response. Neoplasia 7: 667-677, 2005.

36. Valli C, Paroni G, Di Francesco AM, Riccardi R, Tavecchio M, Erba E, Boldetti A, Gianni' M, Fratelli M,Pisano C, et al: Atypical retinoids ST1926 and CD437 are S phase-specific agents causing DNA double-strand breaks: Significance for the cytotoxic and antiproliferative activity. Mol Cancer Ther 7: 2941-2954, 2008.

37. Sun SY and Lotan R: Retinoids and their receptors in cancer development and chemoprevention. Crit Rev Oncol Hematol 41: 41-55, 2002.

38. Livak KJ and Schmittgen TD: Analysis of relative gene expression data using real-time quantitative PCR and the $2^{-\Delta \Delta C \mathrm{~T}}$ method. Methods 25: 402-408, 2001.

39. Tomayko MM and Reynolds CP: Determination of subcutaneous tumor size in athymic (nude) mice. Cancer Chemother Pharmacol 24: 148-154, 1989.

40. Sala F, Zucchetti M, Bagnati R, D'Incalci M, Pace S, Capocasa F and Marangon E: Development and validation of a liquid chromatography-tandem mass spectrometry method for the determination of ST1926, a novel oral antitumor agent, adamantyl retinoid derivative, in plasma of patients in a Phase I study. J Chromatogr B Analyt Technol Biomed Life Sci 877: 3118-3126, 2009. 
41. Hemann MT and Lowe SW: The p53-Bcl-2 connection. Cell Death Differ 13: 1256-1259, 2006.

42. Zuco V, Benedetti V, De Cesare M and Zunino F: Sensitization of ovarian carcinoma cells to the atypical retinoid ST1926 by the histone deacetylase inhibitor, RC307: Enhanced DNA damage response. Int J Cancer 126: 1246-1255, 2010.

43. Fratelli M, Fisher JN, Paroni G, Di Francesco AM, Pierri F, Pisano C, Godl K, Marx S, Tebbe A, Valli C, et al: New insights into the molecular mechanisms underlying sensitivity/resistance to the atypical retinoid ST1926 in acute myeloid leukaemia cells: The role of histone H2A.Z, cAMP-dependent protein kinase A and the proteasome. Eur J Cancer 49: 1491-1500, 2013.

44. Aouad P, Saikali M, Abdel-Samad R, Fostok S, El-Houjeiri L, Pisano C, Talhouk R and Darwiche N: Antitumor activities of the synthetic retinoid ST1926 in two-dimensional and three-dimensional human breast cancer models. Anticancer Drugs 28: 757-770, 2017.

45. Schulz TF: KSHV/HHV8-associated lymphoproliferations in the AIDS setting. Eur J Cancer 37: 1217-1226, 2001.

46. Carbone A and Gloghini A: KSHV/HHV8-associated lymphomas. Br J Haematol 140: 13-24, 2008.

47. Wies E, Mori Y, Hahn A, Kremmer E, Stürzl M, Fleckenstein B and Neipel F: The viral interferon-regulatory factor-3 is required for the survival of KSHV-infected primary effusion lymphoma cells. Blood 111: 320-327, 2008.

48. Degos L and Wang ZY: All trans retinoic acid in acute promyelocytic leukemia. Oncogene 20: 7140-7145, 2001.

49. Hassan M, Watari H, Abu Almaaty A, Ohba Y and Sakuragi N: Apoptosis and molecular targeting therapy in cancer. BioMed Res Int 2014: 150845, 2014.
50. Di Francesco AM, Meco D, Torella AR, Barone G, D'Incalci M, Pisano C, Carminati P and Riccardi R: The novel atypical retinoid ST1926 is active in ATRA resistant neuroblastoma cells acting by a different mechanism. Biochem Pharmacol 73: 643-655, 2007.

51. Petre CE, Sin SH and Dittmer DP: Functional p53 signaling in Kaposi's sarcoma-associated herpesvirus lymphomas: Implications for therapy. J Virol 81: 1912-1922, 2007.

52. Florea AM and Büsselberg D: Cisplatin as an anti-tumor drug: Cellular mechanisms of activity, drug resistance and induced side effects. Cancers 3: 1351-1371, 2011.

53. Hühn D, Bolck HA and Sartori AA: Targeting DNA double-strand break signalling and repair: Recent advances in cancer therapy. Swiss Med Wkly 143: w13837, 2013.

54. Zannini L, Delia D and Buscemi G: CHK2 kinase in the DNA damage response and beyond. J Mol Cell Biol 6: 442-457, 2014.

55. O'Neill KL, Huang K, Zhang J, Chen Y and Luo X: Inactivation of prosurvival $\mathrm{Bcl}-2$ proteins activates $\mathrm{Bax} / \mathrm{Bak}$ through the outer mitochondrial membrane. Genes Dev 30: 973-988, 2016.

56. Luppi M, Trovato R, Barozzi P, Vallisa D, Rossi G, Re A, Ravazzini L, Potenza L, Riva G, Morselli M, et al: Treatment of herpesvirus associated primary effusion lymphoma with intracavity cidofovir. Leukemia 19: 473-476, 2005.

57. Cho HJ, Jeong SG, Park JE, Han JA, Kang HR, Lee D and Song MJ: Antiviral activity of angelicin against gammaherpesviruses. Antiviral Res 100: 75-83, 2013.

58. Williamson SJ, Nicol SM, Stürzl M, Sabbah S and Hislop AD: Azidothymidine sensitizes primary effusion lymphoma cells to Kaposi sarcoma-associated herpesvirus-specific CD4 ${ }^{+} \mathrm{T}$ cell control and inhibits vIRF3 function. PLoS Pathog 12: e1006042, 2016. 